\title{
Féeries
}

Études sur le conte merveilleuX, XVII ${ }^{-}$XIXe siècle

9 | 2012

Le dialogisme intertextuel des contes des Grimm

\section{C'est la plume qui fait le conte : Die sechs Schwäne des frères Grimm et De vilde Svaner de Hans Christian Andersen}

It is the pen which makes the tale. the Grimm brothers' Die sechs Schwäne and Christian Andersen's De vilde Svaner

\section{Cyrille François}

\section{OpenEdition}

Journals

Édition électronique

URL : http://journals.openedition.org/feeries/819

ISSN : 1957-7753

Éditeur

UGA Éditions/Université Grenoble Alpes

Édition imprimée

Date de publication : 15 octobre 2012

Pagination : 55-84

ISBN : 978-2-84310-233-2

ISSN : 1766-2842

Référence électronique

Cyrille François, «C'est la plume qui fait le conte : Die sechs Schwäne des frères Grimm et De vilde Svaner de Hans Christian Andersen », Féeries [En ligne], 9 | 2012, mis en ligne le 15 octobre 2013, consulté le 07 septembre 2020. URL : http://journals.openedition.org/feeries/819 


\title{
Cyrille François
}

Centre de recherches en langues et littératures européennes comparées (CLE),

Université de Lausanne

\section{C’EST LA PLUME QUI FAIT LE CONTE :}

\author{
DIE SECHS SCHWÄNE DES FRÈRES GRIMM ET DE VILDE SVANER \\ DE HANS CHRISTIAN ANDERSEN
}

$L$

ES CONTES DES FRĖRES GRIMM et ceux de Hans Christian Andersen sont en grande partie indissociables. L'histoire de leurs éditions, traductions et rééditions indique que le lectorat européen les a en général reçus comme deux représentants d'un même genre, et il est courant de les trouver côte à côte dans des recueils pour enfants. Cependant, ils présentent d'importantes différences stylistiques et thématiques, relevées par plusieurs commentateurs, qui montrent bien que le genre de «conte de fées international» dans lequel on les réunit ne correspond ni aux eventyr d'Andersen ni aux Märchen des Grimm ${ }^{1}$. Une comparaison permet de mieux comprendre le lien qu'entretiennent ces textes, en partie contemporains, si proches et si différents à la fois. Si certaines éditions se chevauchent, il faut toutefois relever qu'Andersen commence la publication de son premier cahier de contes plus de vingt ans après le premier recueil des Grimm, qui est entre-temps devenu populaire au Danemark. Il en résulte que l'auteur danois peut difficilement ne pas connaître le projet des Grimm et que, volens nolens, il inscrit ses textes dans un genre en grande partie défini par les Kinder-und Hausmärchen (Contes de l'enfance et du foyer, ci-après KHM).

Cet article étudie le type de dialogue intertextuel à l'œuvre entre Andersen et les Grimm dans la lignée de la méthode comparatiste mise en œuvre par Ute Heidmann pour montrer que les Histoires ou contes du temps passé de Perrault témoignent d'un «dialogisme intertextuel très complexe avec les formes génériques du conte déjà existantes dans les littératures européennes",

I. Voir C. Dollerup, Tales and Translation, 1999, p. x.

2. U. Heidmann, "Expérimentation générique et dialogisme intertextuel», 20II, p. 45. Voir également l'article d'U. Heidmann dans ce numéro et C. François, «Échanges et dialogues intertex- 
et que les KHM fonctionnent sur le même mode. La comparaison de Die sechs Schwäne (Les six cygnes), paru dès l'édition I8I2 des KHM, et de De vilde Svaner (Les cygnes sauvages), publié dans le premier cahier du nouveau recueil d'Eventyr, fortalte for Børn (Contes, racontés aux enfants) de I838, permet d'évaluer la complexité de la situation. D'une part, il est évident à la lecture des textes des Grimm et d'Andersen que l'auteur danois se positionne par rapport aux KHM lorsqu'il écrit son eventyr, mais d'autre part, il n'est pas certain qu'Andersen ait été influencé par le conte des Grimm, car il s'inspire d'un texte danois pour rédiger le sien. De vilde Svaner est en outre particulièrement intéressant pour cette étude, car il s'agit d'un conte très proche du genre de la nouvelle, qui développe au plus haut point certaines caractéristiques des eventyr d'Andersen.

Je comparerai dans un premier temps plusieurs textes allemands et danois de la première moitié du XIX ${ }^{\mathrm{e}}$ siècle, racontant des histoires de frères transformés en cygnes qui retrouvent leur forme humaine grâce à leur sœur. Il s'agira de voir si des indices permettent d'avancer qu'Andersen aurait utilisé Die sechs Schwäne comme intertexte. Dans un second temps, l'analyse portera sur la manière de raconter propre à chaque auteur, en relation avec un projet discursif différent. À une époque où les KHM ont fait de nombreux émules au Danemark, avec leur logique narrative très linéaire et la tendance à effacer la présence du narrateur, il faut en effet considérer les stratégies narratives des eventyr d'Andersen, qui font exploser les structures des contes inspirés des KHM et qui convoquent un narrateur omniprésent, comme une volonté de créer un genre différent de celui dont les Grimm sont à la fois les créateurs et les principaux représentants. La comparaison de Die sechs Schwäne et de De vilde Svaner suggère ainsi que ce ne sont pas tant les motifs ou l'histoire qui font le conte, mais plutôt la manière de raconter propre à chaque auteur : sa plume.

\section{Le dialogue des histoires d'enfants-cygnes}

Die sechs Schwäne et De vilde Svaner s'inscrivent dans une série de textes racontant des histoires semblables ${ }^{3}$. Même si les Grimm et Andersen sou-

tuels», 20II. Les recherches du CLE ont donné lieu à plusieurs publications comparant les Grimm et Andersen : J.-M. Adam et U. Heidmann, Le Texte littéraire, 2009, chap. 2 et 3 ; C. François, «Transcrire ou raconter à sa façon», 2009.

3. Je focalise ici sur les frères transformés en cygnes, mais les Grimm eux-mêmes font un parallèle avec Die sieben Raben (KHM 25; Les sept corbeaux) : «Il est en rapport avec le conte des sept corbeaux $\left(n^{\circ} 25\right)$, si ce n'est qu’il s’agit ici de cygnes blancs, car les enfants ont été ensorcelés sans avoir commis 
tiennent que leurs textes sont des contes populaires respectivement allemand et danois ${ }^{4}$, on peut les mettre en relation directe avec des textes publiés dans des livres. Il n'est pas possible d'affirmer que ces histoires étaient ou n'étaient pas dites par oral à cette époque, mais on peut en revanche mettre à jour des sources jalonnant la transmission de cette histoire de cygnes et faisant le lien, par l'écrit, entre les KHM des Grimm et l'eventyr d'Andersen. Chacun de ces jalons introduit de nouveaux éléments dans une histoire plus ancienne, qui sont ensuite repris par les textes suivants, de sorte qu'il est possible de reconstruire une généalogie de la légende médiévale du Dolopathos au conte d'Andersen, en passant par le recueil anonyme de I8OI intitulé Feen-Mährchen (Contes de fées), les KHM, et les Danske Folkeeventyr (Contes populaires danois) de Mathias Winther.

\section{Le Dolopathos}

Historia septem sapientium, plus connu sous le nom de Dolopathos, est un recueil à récit-cadre du moine Jean de Haute-Seille, rédigé à la fin du $\mathrm{XII}^{\mathrm{e}}$ siècle ${ }^{5}$. L'histoire du septième sage présente la plus ancienne occurrence de transformation d'enfants en cygnes. Un jeune homme noble rencontre une nymphe vierge alors qu'il chasse une biche blanche. Il en tombe amoureux et l'épouse, causant ainsi la jalousie de sa mère qui se sent menacée par l'arrivée de sa bru. Cette dernière accouche de six garçons et une fille que la belle-mère remplace par des chiots. Le chevalier répudie sa femme dont le châtiment est de vivre enterrée jusqu'à la poitrine au milieu de son palais. La belle-mère finit par apprendre que les enfants n’ont pas été tués comme

la moindre faute.» ("Es hängt mit dem Märchen von den sieben Raben (Nr. 25) zusammen, nur sind es hier weiße Schwäne, weil die Kinder ganz ohne Schuld verwünscht wurden. "; Grimm, Kinder- und Hausmärchen, 1857, vol. 3, p. 8I, je traduis.) Pour une comparaison de trois KHM thématiquement proches, voir R. B. Bottigheimer, «Motif, Meaning, and Editorial Change in Grimms' Tales», 1990.

4. Dans ses «Remarques» ("Bemarkninger»), Andersen indique: "Les Cygnes sauvages est en revanche donné d'après un conte populaire danois" ("De vilde Svaner er derimod givet efter et dansk Folke-Eventyr»; H. C. Andersen, Eventyr, 1963-1990, vol. 6, p. 5, je traduis). Si le terme Volksmärchen (conte populaire) n'est présent que dans la préface des KHM de I8Is (le deuxième volume de la première édition), celle de I8I2 insiste déjà sur le fait que les textes du recueil ont été recueillis par oral et que c'est la tradition orale qui a sauvegardé ces derniers spécimens de la "poésie allemande des premiers temps" (voir Grimm, Contes pour les enfants et la maison, 2009, vol. I, p. 472-473, traduction de Grimm, Kinder- und Hausmärchen, I8I2, p. v-VII). Pour une analyse des propos des Grimm concernant la "tradition orale» et leur "collecte», voir la contribution d'U. Heidmann infra.

5. Sur le Dolopathos, voir l'introduction à la traduction française par Y. Foehr-Janssens et E. Métry (Jean de Haute-Seille, Dolopathos, 2000, p. 5-33), ainsi que L. Harf-Lancner (Les Fées au Moyen Âge, 1984, p. 179-198). Dans le numéro 7 de Féeries (p. 2I-43), R. B. Bottigheimer commente ce texte dans le cadre de son étude sur «Les contes médiévaux et les contes de fées modernes», 2010. 
elle l'ordonnait et qu'ils vivent dans la forêt. Elle leur fait dérober le seul signe qui les relie à son fils : les chaînes d'or qu'ils portent autour du cou et qui les empêchent de se transformer en cygnes. Seule la sœur parvient à conserver la sienne. Le chevalier reconnaît un jour sa fille et apprend toute la vérité. Les cygnes retrouvent alors leurs chaînes d'or et leur forme humaine, à l'exception d'un des frères dont la chaîne a été brisée. La bellemère est enterrée jusqu'à la poitrine à la place de sa bru. Contrairement aux textes suivants, les frères ne sont pas ensorcelés; leur statut mi-humain mi-animal provient du fait qu'ils sont issus de l'union d'un homme et d'une créature surnaturelle. Pour qu'ils regagnent leur forme humaine, il ne faut ainsi pas les désensorceler à l'aide de chemises, mais leur rendre un bien (la chaine d'or) qui leur a été dérobé. De plus, les cygnes ne parlent pas et n'expliquent pas à leur sœur comment les sauver; cette dernière ne contribue d'ailleurs pas beaucoup au dénouement heureux, dont le mérite revient plutôt au père.

Ce récit a été repris comme introduction de la légende du chevalier au cygne et popularisé sous deux versions, Elioxe et Beatris. Le lien avec la légende du chevalier au cygne est d'ailleurs explicite dans le texte, qui précise au sujet du frère qui ne retrouve pas sa forme humaine : "C'est ce cygne dont la rumeur dit aujourd'hui encore qu'il tirait au bout d'une chaîne d'or un chevalier en arme sur une barque ${ }^{6} »$. Il a aussi été adapté et traduit de nombreuses fois. Willem de Blécourt mentionne plusieurs traductions allemandes, dont deux entre I780 et I80o qui fournissent sûrement la base de Die sieben Schwäne, paru dans le recueil anonyme Feen-Mährchen en I80I ${ }^{7}$. Ludwig Bechstein a quant à lui repris une traduction en moyen hautallemand tardif du Dolopathos, publiée dans Altdeutsche Blätter par Moriz Haupt et August Heinrich Hoffmann von Fallersleben ${ }^{8}$, pour rédiger Die sieben Schwanen, paru dans son Deutsches Märchenbuch (Livre de contes allemand) de 1845.

Le texte du Dolopathos est l'intertexte commun des contes des Grimm et d'Andersen. Les auteurs allemands en sont d'ailleurs très familiers, puisqu'ils publient cinq textes liés à la légende du chevalier au cygne dans leurs Deutsche Sagen (Légendes allemandes), dont une version de Beatris sous le titre Der Ritter mit dem Schwan (Le chevalier au cygne; DS 540).

6. J. de Haute-Seille, Dolopathos, 2000, p. 197.

7. W. de Blécourt, «Metamorphosing Men and Transforming Texts», 20II, p. 285.

8. Altdeutsche Blätter (vol. I, I836, p. I28-136). Les Grimm font référence à ce texte dans leurs notes (Grimm, ouvr. cité, 1857, vol. 3, p. 85) et empruntent eux-mêmes aux Altdeutsche Blätter le conte «Der Räuber und seine Söhne» («Le brigand et ses fils»; Anh. 28). 


\section{Die sieben Schwäne (Feen-Mährchen, I80I)}

Die sieben Schwäne est un chaînon important entre le Dolopathos et les textes des Grimm et d'Andersen. Il amorce un profond travail de «reconfiguration", notamment en décalant l'histoire d'une génération : le héros initial ne rencontre pas la mère des cygnes, mais il a déjà des enfants que sa femme transformera en cygnes, et c'est sa fille, et non sa femme, qui subit l'ire d'une méchante belle-mère. Comme dans le Dolopathos, c'est en poursuivant une biche blanche qu'un chasseur s'égare dans une forêt, où il rencontre une femme qui vit recluse dans un château isolé. Suite à une longue scène de séduction avinée et explicite, il épouse cette femme voluptueuse et de peu de vertu qui tente de séduire son fils aîné. Ce dernier, refusant les avances de sa belle-mère, est transformé en cygne, de même que ses frères qui tentent de lui venir en aide. N'étant pas privés de la parole, ils peuvent toutefois expliquer à leur sœur qu' elle peut les sauver en cousant sept chemises en sept ans, sans parler ni pleurer. Un roi la découvre dans la forêt, en tombe amoureux et l'épouse, mais, pendant qu'il est à la guerre, sa mère, hostile à cette union, subtilise le nouveau-né de sa bru et fait croire que cette dernière l'a mangé, sans totalement convaincre le roi. Elle remplace ensuite les deux filles d'une seconde couche par des chatons, et le roi condamne alors sa femme au bûcher. Les chemises sont heureusement terminées à temps et les frères apparaissent sains et saufs, à l'exception d'un des frères auquel la larme versée par sa sœur lors des sept ans de labeur a causé la perte d'un œil. La vérité est alors révélée et la belle-mère se suicide. Les frères retrouvent ensuite leur père, qui s'était entre-temps débarrassé de sa méchante femme. Le texte se termine comme il a commencé, avec une famille unie et heureuse : «Ils ne formèrent à l'avenir qu'une famille" ».

Plusieurs éléments de ce texte sont proches de celui du Dolopathos, mais des changements majeurs sont opérés. Le chasseur rencontre une femme aux pouvoirs surnaturels, mais là où il s'agissait d'un personnage positif dans le Dolopathos, il s'agit ici d'une méchante fée. On retrouve la substitution des nouveau-nés par des animaux (des chiots dans le Dolopathos, des chatons ici), mais ce texte ajoute le motif du cannibalisme qui sera repris par les Grimm, de même que celui de la rencontre du roi et de l'héroïne dans un arbre.

9. "Sie machten in der Folge nur eine Familie aus»; U. Marzolph, Feen-Mährchen, 2000, p. 293, je traduis. 


\section{Die sechs Schwäne (Grimm, I8I2)}

Si les Grimm prétendent que Die sechs Schwäne leur a été transmis par oral, il est évident, comme le soutient Heinz Rölleke ${ }^{\mathrm{ro}}$, qu'il «semble, au moins indirectement, influencé» par le texte des Feen-Mährchen ${ }^{\text {II }}$. Les auteurs connaissent ce recueil qu'ils mentionnent dans une note de leur préface de I8r2. Ils le considèrent comme l'un des plus riches recueils de contes populaires, bien que les contes y soient racontés sur un «ton inapproprié » ( in verkehrtem Ton $\left.{ }^{12} »\right)$. C'est en effet surtout la tonalité du conte qui est transformée : les Grimm expurgent le texte de ses connotations sexuelles et rendent le père plus valeureux. Ce dernier ne succombe pas au plaisir charnel mais est forcé d'épouser la fille d'une sorcière pour ne pas mourir dans la forêt où il s'est égaré. De plus, contrairement au père de Die sieben Schwäne, il a le réflexe de protéger ses enfants contre sa nouvelle femme, même si ses précautions ne suffisent pas. De son côté, la fille est plus active : elle part à la recherche de ses frères sans qu'ils lui demandent de les sauver et décide de leur venir en aide contre leur avis. Outre ces transformations portant sur le caractère des personnages, plusieurs éléments nouveaux font leur apparition. Premièrement, les cygnes retrouvent leur apparence humaine tous les soirs, pendant quinze minutes, ce qui permet une scène de reconnaissance et évite de faire parler des cygnes. Deuxièmement, il n'y a pas de substitution des nouveau-nés par des animaux : la belle-mère accuse l'héroïne de cannibalisme à chaque reprise. Enfin, le plus jeune des frères garde des séquelles de sa métamorphose, comme dans le texte des Feen-Mährchen, mais pas à l'œil : il conserve une aile à la place du bras gauche, car il manquait une manche à la dernière chemise ${ }^{\mathrm{r} 3}$. Au niveau de la progression thématique, il est intéressant de voir comment les Grimm exploitent le motif des chemises, qui parcourt tout le texte : la belle-mère

Io. H. Rölleke montre que le texte, modifié d'édition en édition, se voit affublé en I8ı d'une citation tirée d'une ballade de J. F. von Eichendorff, publiée en I8Is dans son roman Ahnung und Gegenwart (H. Rölleke, "Ein Eichendorff-Zitat in den KHM der Brüder Grimm », 1985). Cette citation littéraire ne peut donc pas provenir du conte qu'ils auraient entendu d'H. Dorothea Wild en I8I2.

II. Grimm, Kinder- und Hausmärchen, I857, vol. 3, p. 463.

I2. Grimm, Kinder- und Hausmärchen, I8I2, p. XIx.

13. Notons en passant que pendant les six ans (sept dans le texte de I8OI car il y avait sept cygnes) où elle doit tisser les chemises, l'héroïne a le droit de pleurer chez les Grimm, mais pas de rire. Le texte indique également que les chemises doivent être cousues à partir d'Aster (Sternblume, littéralement «fleur d'étoile»), ce qui explique, comme le rappelle N. Rimasson-Fertin, une remarque de la première préface : «Le soleil, la lune, les étoiles sont accessibles, ils font des cadeaux aux personnages et acceptent même qu'on les tisse pour en faire des habits" (Grimm, Contes pour les enfants et la maison, 2009, vol. I, p. 279). 
transforme les frères en leur jetant des chemises ensorcelées dessus; ces derniers retrouvent leur forme humaine quinze minutes par jour en retirant leur plumage comme des chemises; ils sont finalement désensorcelés à l'aide des chemises cousues par leur sœur. On voit ainsi la recherche de cohérence du conte des Grimm par la reprise et le développement des mêmes motifs.

\section{De elleve Svaner (Winther, I823)}

De elleve Svaner (Les onze cygnes) a paru en 1823 dans Danske Folkeeventyr, le premier recueil de contes populaires danois récoltés selon les préceptes des Grimm. Winther, médecin militaire et bibliothécaire originaire d'Odense, tout comme Andersen, ne mentionne les KHM ni dans sa préface ni dans ses remarques, mais il cite d'autres œuvres des auteurs allemands, qu'il connaît sûrement très bien par son collègue Just Mathias Thiele, correspondant des Grimm et l'un des premiers à reprendre leur projet au Danemark avec son recueil de Légendes populaires danoises (Danske Folkesagn, à partir de I8I8). Le premier volume des KHM était d'ailleurs traduit en danois depuis I82I (trad. Johan Frederik Lindencrone) et W. de Blécourt indique qu'une traduction de Die sechs Schwäne circulait sous forme de chapbook en Suède en I $824^{14}$. Même si Winther assure avoir recueilli De elleve Svaner par oral, il est donc très probable qu'il ait lu le texte des Grimm dont il reprend certains éléments que le Märchen associe pour la première fois à l'histoire des enfantscygnes. Premièrement, les cygnes retrouvent leur forme humaine tous les soirs, quinze minutes chez les Grimm, toute la nuit chez Winther (comme chez Andersen). Deuxièmement, l'un des frères conserve une aile de cygne à la place d'un bras car l'héroïne n'a pas eu le temps de terminer une des manches de la dernière chemise. Troisièmement, la scène des retrouvailles entre frères et sœurs a lieu dans la hutte/maison où se réfugient les frères lorsqu'ils reprennent leur forme humaine.

Que Winther ait eu le Märchen des Grimm sous les yeux ou non lorsqu'il écrivait son folkeeventyr, il ne fait aucun doute qu'il y a un lien entre les deux textes. Cependant, l'auteur danois introduit à son tour plusieurs éléments qu'on ne trouvait pas dans les textes précédents et qui seront le plus souvent repris par Andersen. Le titre même indique que le nombre de protagonistes change : sept frères dans le texte des Feen-Mährchen, six dans ceux du Dolopathos et des Grimm, onze dans ceux de Winther et d'Andersen. Le caractère des personnages est très intéressant aussi, car là où les Grimm présentaient un texte centré sur la famille, avec un père

I4. W. de Blécourt, art. cité, p. 286. 
obligé de se remarier mais tout de même assez prévoyant pour mettre ses enfants à l'écart, le conte de Winther n'explique pas pour quelle raison le père épouse une sorcière et ce dernier ne fait rien pour protéger le fruit de son premier mariage. L'héroïne, en revanche, est encore plus entreprenante que chez les Grimm : lorsqu' elle part à la recherche de ses frères, elle pense à prendre certains de leurs effets personnels pour qu'ils la reconnaissent; elle les capture à l'aide de filets pour les empêcher de s'échapper. Winther introduit ensuite le personnage de la vieille sorcière dans la forêt qui aide l'héroïne à retrouver ses frères (Andersen en fait le personnage de la fée Morgane qui explique également à Élisa comment sauver ses frères). En ce qui concerne les épreuves à subir pour retransformer les cygnes en hommes, c'est le frère aîné qui en informe sa sœur, comme chez les Grimm, mais Winther introduit le motif du rêve. Chez Andersen aussi les instructions sont données dans un rêve, mais celui d'Élisa qui rencontre la fée Morgane. De elleve Svaner présente également une nouveauté en ce qui concerne l'épreuve des chemises, qui doivent être tissées à partir de chardons. En plus du long silence auquel l'héroïne est contrainte, cette tâche entraîne désormais une souffrance physique liée au traitement de cette plante épineuse. Ce sera un élément repris et développé par Andersen, qui utilise des orties et met l'accent sur la pénibilité du travail ${ }^{15}$ :

Med de fine Hander greb hun ned i de haslige Nalder, de vare som Ild; store Vabler brandte de paa hendes Honder og Arme, men gjerne vilde hun lide det, kunde hun frelse de kjare Brodre ${ }^{16}$.

Elle plongea ses mains délicates parmi les affreuses orties, elles étaient comme du feu. Elles firent de grosses cloques sur ses mains et ses bras, mais elle acceptait volontiers ces souffrances si seulement elle pouvait sauver ses chers frères ${ }^{17}$.

Le lieu du dénouement est un autre élément introduit par Winther et repris par Andersen : si les héroïnes sont condamnées dans tous les contes, celle des Grimm est déjà sur le bûcher sur le point d'être allumé quand elle est sauvée, alors que les deux textes danois présentent un convoi en charrette vers le lieu d'exécution pendant lequel les frères apparaissent et retrouvent leur forme humaine.

De elleve Svaner suit ainsi Die sechs Schwäne sur plusieurs points et prend parfois ses distances en introduisant de nouveaux éléments à cette histoire

I5. Les souffrances endurées par Élisa ne sont pas sans rappeler la Petite Sirène, autre personnage réduit au silence qui endure une douleur extrême.

I6. H. C. Andersen, Eventyr, I963-1990, vol. I, p. I33.

17. H. C. Andersen, Contes et histoires, 2005, p. 204-205. 
des enfants-cygnes. Il est intéressant de relever qu'il arrive aussi que le texte de Winther se rapproche de la légende médiévale là où les Grimm s'en éloignaient. Winther reprend par exemple le motif des nouveau-nés remplacés par des chiots, et n'exploite pas les accusations de cannibalisme proférées par la belle-mère des KHM. Comme dans le texte des Feen-Mährchen, les manigances de cette dernière s'effectuent lorsque le roi est à la guerre, alors qu'il est présent chez les Grimm, mais trop bon pour croire sa femme coupable et trop naïf pour soupçonner sa mère. Rien ne permet toutefois de savoir si Winther a lui-même lu le Dolopathos, peut-être en traduction, et les Feen-Mährchen, ou si ces textes circulaient dans la tradition orale danoise, d'où Winther dit avoir tiré De elleve Svaner ${ }^{18}$.

\section{De vilde Svaner (Andersen, ${ }_{1} 8_{3} 8$ )}

L'extrême concision du conte de Winther est remarquable en comparaison du long texte qu'il a inspiré à Andersen. Ce dernier a développé le fruste canevas de De elleve Svaner en y ajoutant plusieurs scènes et de nombreuses descriptions. Le narrateur présente l'héroïne, prénommée Élisa (alors qu'elle reste anonyme dans les autres textes), de manière empathique en faisant connaître sa valeur et son caractère dans des passages d'harmonie totale entre cette jeune fille et la nature. Les nuits qu' elle passe dans la forêt avant de retrouver ses frères sont ainsi très intéressantes au niveau thématique, et nous verrons, au niveau linguistique, qu'elles entraînent des stratégies particulières pour traduire cette empathie, notamment en ce qui concerne la représentation des paroles ${ }^{19}$. Andersen ajoute également un voyage à la fois merveilleux et angoissant par-dessus les océans, lors duquel Élisa est transportée par ses frères dans un filet. Ces différents ajouts, associés à des caractéristiques linguistiques décrites ci-dessous, contribuent à inscrire ce texte dans un genre souvent plus proche de la nouvelle que du conte.

On a vu qu'Andersen reprenait plusieurs des éléments nouveaux apportés par le conte de Winther, ce qui semble confirmer que c'est bien le texte dont il s'inspire, comme il l'évoque lui-même dans une lettre à B. S. Ingemann : "Lisez dans les contes de Winther celui sur "les cygnes sauvages", et dites s'il est bien ou mal réécrit chez moi.» ("Las i Mathias Winthers Eventyr det

I8. Notons qu'il n’a pas transcrit le texte lui-même, mais qu'il lui a été communiqué par l'une des deux personnes remerciées en préface, J. M. Thiele ou J. Grønvald (M. Winther, Danske Folkeeventyr, I823, p. XVI).

19. Et historique, pourrait-on ajouter, puisqu' elles inscrivent Andersen dans le courant romantique danois du début du XIX ${ }^{e}$ siècle. Le passage se trouve, en danois, dans H. C. Andersen, ouvr. cité, I963-1990, vol. I, p. I27-I29; en français, H. C. Andersen, Contes et histoires, 2005, p. 195-198. 
om "de vilde Svaner", og siig, om det er godt eller slet omdigtet hos mig. ") ${ }^{20} \mathrm{Ce}$ travail de réécriture concerne bien évidemment la manière de raconter, avec par exemple l'ajout de descriptions évoqué ci-dessus, mais aussi quelques changements plus conséquents dans l'histoire ${ }^{21}$. L'héroïne d'Andersen est bien moins active que celle de Winther : elle ne part pas d'elle-même pour secourir ses frères, mais est chassée de la maison par son père (qui ne la reconnaît pas, suite à un mauvais tour de la belle-mère); elle ne capture pas les cygnes avec des filets, mais est au contraire transportée par ces derniers dans un filet après avoir accepté de les suivre ${ }^{22}$. Selon Wolff Lundholt et Krogh Hansen, "the "narrative [s]" of Andersen's tales are not a matter of the protagonists gaining experience which in the end will lead them to insights about themselves", mais le dénouement découle naturellement "in the sense that it obeys the (metaphysical) logic Andersen in general follows- that man will be led to happiness by God, if only he stay pure at heart ${ }^{23}$ ". Ceci explique en partie pourquoi le texte d'Andersen est moins tourné vers l'action que les autres et qu'il développe plus longuement des détails dont le but n'est autre que de confirmer la vertu de l'héroïne (les crapauds ensorcelés qui ne l'affectent pas, les fleurs sur le bûcher, les animaux qui l'aident dans sa cellule, les statues, le recueil de cantique, les cloches, les arbres, etc.). Élisa est moins active que les héroïnes des autres contes, car ce ne sont pas tant par leurs actes que les personnages d'Andersen sont jugés que par leurs vertus. Celle d'Élisa est récompensée par l'aide de la fée Morgane, alors que l'héroïne de Die sechs Schwäne ne reçoit aucune aide magique.

Le conte d'Andersen supprime deux motifs communs dans l'histoire des enfants-cygnes. En premier lieu, l'héroïne n'est pas calomniée par sa bellemère : il n'est pas question de bébés substitués par des chiots comme chez Winther, ni même de cannibalisme comme chez les Grimm. En second lieu,

20. Lettre du 5 octobre 1838, citée dans H. C. Andersen, ouvr. cité, 1963-1990, vol. 7, p. 44, je traduis. Dans sa réponse du 9 octobre I838, B. S. Ingemann félicite Andersen de la suppression de certains " traits cruels ou entendus", comme la substitution des bébés par des chiots ou le châtiment de la belle-mère dans un tonneau rempli de clous (K. Dreyer, H. C. Andersen - en brevbiografi, 2004, lettre 223).

2I. Sur un point, Andersen rejoint même les Grimm en s'éloignant de Winther : le roi refuse de croire à la culpabilité de sa femme et c'est le peuple qui la condamne.

22. Andersen a été marqué par une scène de l'Oberon de C. M. von Weber (livret de J. R. Planché basé sur un poème de Ch. M. Wieland) qui n'est pas sans rappeler ce voyage. Après une représentation à Berlin le I2 juin I83ı, il écrit dans son journal : "Obéron naviguait sur un coquillage tiré par des cygnes" ("Oberon seilede paa en Musling trukket af Svaner»; H. C. Andersen, H. C. Andersens Dagbøger, 197I-1977, p. I07, je traduis; voir C. M. Weber, Obéron, I985, p. 60). Relevons en passant que le livret a été traduit en danois par A. Oehlenschläger, qui était un ami de C. M. Weber.

23. M. Wolff Lundholt et P. Krogh Hansen, When We Get to the End, 2005, p. I4. 
l'histoire ne se termine pas par un châtiment (bûcher pour la belle-mère chez les Grimm, tonneau à clous chez Winther). Ces deux changements proviennent du fait qu'Élisa n'a pas de belle-mère malfaisante, car le personnage négatif de la fin de l'histoire est remplacé par un archevêque ${ }^{24}$.

\section{Grimm et Andersen : quel type de dialogue?}

Les textes présentent plus que de petites différences dans l'utilisation ou non de certains motifs, c'est l'ensemble de l'histoire qui est transformé lorsqu'elle est racontée dans un contexte différent. Le Dolopathos, par exemple, raconte plusieurs histoires exemplaires "pour mettre en garde un roi contre les actions inconsidérées, en l'occurrence l'exécution de son propre fils, que sa seconde femme a accusé d'agression sexuelle sur sa personne ${ }^{25}$ ». Comme dans le Pentamerone de Basile, le récit-cadre conditionne le type de récits à raconter et la moralité de ces derniers. Pour faire comprendre au roi que sa femme calomnie son fils, l'un des sept sages lui raconte cette histoire d'enfants-cygnes dont la moralité « dit en substance qu'il faut bien se protéger des mauvaises femmes, fort nombreuses et diaboliques ${ }^{26}{ }^{2}$. Dans les Feen-Mährchen et les KHM, l'accent est mis sur la famille, avec l'arrivée d'une belle-mère qui peut mettre en péril le bonheur familial, et une fin heureuse où la famille est recomposée. Le mariage forcé ne fonctionne pas dans Die sechs Schwäne, seul le mariage consenti crée une famille heureuse. De plus, la famille triomphe finalement des tromperies : le texte débute en effet avec un roi trompé par une sorcière et se termine par une femme brûlée comme une sorcière; dans les deux cas, il s'agit de belles-mères qui forcent leur gendre au mariage ou calomnient leur bru. Relevons en outre que les enfants-cygnes sont eux-mêmes trompés par leur belle-mère qu'ils prennent pour leur père.

Le texte d'Andersen, quant à lui, ne raconte pas seulement l'histoire de la reconstitution d'une famille unie, mais aussi celle d'une restauration sociale. Le début du texte insiste sur la vie luxueuse que mènent les enfants (l'ardoise en or, le crayon en diamant, le livre qui vaut la moitié du royaume, etc.) et dont la description s'achève par cette remarque du narrateur en guise de nœud du récit : «mais il ne devait pas en être ainsi pour toujours!» (H. C. Andersen, Contes et histoires, 2005, p. I92; "men

24. Selon les notes de l'édition scientifique danoise, cela illustrerait le refus de toute forme d'autorité et d'orthodoxie religieuse d'Andersen (H. C. Andersen, ouvr. cité, I963-1990, vol. 7, p. 46).

25. R. B. Bottigheimer, art. cité, 20I0, p. 25.

26. L. Bechstein, Le Livre des contes, 2010, p. 319. 
saaledes skulde det ikke altid blive!», H. C. Andersen, Eventyr, I963-1990, vol. I, p. I25.) Le problème est effectivement qu'ils sont rapidement privés de leur statut, tout d'abord en recevant du sable dans une tasse à thé au lieu des gâteaux et des pommes auxquels ils étaient habitués, puis, pour Élisa, en étant placée chez des paysans à la campagne. Elle va même jusqu'à être privée de sa beauté, raison pour laquelle elle est chassée par son père qui ne la reconnaît plus. Cette dimension était absente du texte des KHM, dans lequel le père place les enfants dans un château à l'écart pour les protéger; il n'y a donc pas de perte de statut dans la situation initiale. La fin du texte d'Andersen confirme que ce que retrouve l'héroöne (et ses frères grâce à elle), c'est une incroyable opulence : "Il se forma un cortège de noces comme aucun roi n'en avait encore jamais vu ${ }^{27}$ " ( det blev et Bryllupstog tilbage til Slottet, som endnu ingen Konge havde seet det $\left.{ }^{28} "\right)$.

Au terme de ce premier survol des textes, il ne semble pas qu'Andersen

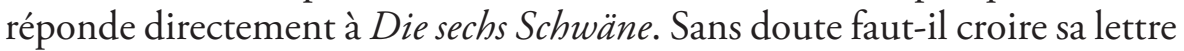
à Ingemann et penser qu'il s'inspire du conte de Winther. De plus, dans sa préface de 1837, Andersen indique justement ne pas avoir trouvé ses contes danois chez un étranger :

I min Barndom horte jeg gjerne Eventyr og Historier, flere af disse staae endnu ret levende $i$ min Erindring; enkelte synes mig at vare oprindelige danske, ganske udsprungne af Folket, jeg har hos ingen Fremmed fundet de samme. Paa min Maade har jeg fortalt dem, tilladt mig enhver Forandring, jeg fandt passende, ladet Phantasien opfriske de $i$ Billederne afblegede Farver ${ }^{29}$.

Dans mon enfance, $\mathrm{j}$ 'aimais bien entendre des contes et des histoires, plusieurs demeurent encore bien vivants dans mon souvenir; certains me semblent bien danois et sortis tout à fait du peuple, chez aucun étranger je n'ai trouvé les mêmes. Je les ai racontés à ma façon, me permettant toutes les modifications que je trouvais convenables, laissant mon imagination aviver les couleurs pâlies des images ${ }^{30}$.

Trois des textes qu'Andersen dit, dans cette préface de 1837, avoir entendus dans son enfance racontent pourtant des histoires proches de celles de Märchen des Grimm : Fyrtøiet (Le briquet) = Das blaue Licht (La lumière bleue); Lille Claus og store Claus (Le petit Claus et le grand Claus) = Das Bürle (Le petit paysan); Prindsessen paa Arten (La Princesse sur le pois) = Die Erbsenprobe (L'épreuve des petits pois; ce dernier texte a paru dans la

27. H. C. Andersen, ouvr. cité, 2005, p. 212; l'omniprésence des oiseaux (les hirondelles au début et une grande variété d'oiseaux à la fin) annonce le thème du conte sur les cygnes.

28. H. C. Andersen, ouvr. cité, 1963-1990, vol. I, p. I38.

29. Ibid., p. 19-20.

30. H. C. Andersen, Euvres, 1992, vol. I, p. 4. 
cinquième édition des KHM, en I843, soit huit ans après la publication de l'eventyr d'Andersen). Ce ne sont pas les textes les plus connus des Grimm (ils ne font d'ailleurs pas partie de la kleine Ausgabe, de même que Die sechs Schwäne qui nous intéresse tout particulièrement) et il est en effet possible qu'Andersen ne les ait pas lus. Même si l'on juge que l'auteur danois dit la vérité et qu'il n'a pas eu connaissance des textes des Grimm, il ne faut toutefois pas sous-estimer le rôle qu'ont joué les KHM dans l'écriture des eventyr d'Andersen, sûrement sur un autre mode que celui de la référence intertextuelle directe. L'auteur danois s'inscrit en effet dès ses premiers contes dans la différence par sa volonté de créer une œuvre personnelle qui se distingue des représentants du genre à son époque. Or, c'est le projet philologique des Grimm qui offre le cadre de référence au Danemark au début du XIX ${ }^{e}$ siècle.

Les KHM se présentent dans leur préface de I8I2 comme un travail visant à sauver les contes populaires de la disparition, qui s'insère dans un projet plus large pour recueillir toutes sortes de littératures populaires (chansons, poèmes, légendes, etc.). Réédités six fois entre I8I9 et I857, les KHM fonctionnent à la manière d'un catalogue auquel des textes sont ajoutés ou duquel d'autres sont supprimés, sans que le titre ni le fonctionnement global n'en soient modifiés.

La volonté d'inscrire ces contes dans un tel livre pour les sauver de la disparition doit être comprise en relation avec leur origine aux yeux des auteurs :

[Le conte] faisait partie, à leur [les Grimm] sens, de la Nationalpoesie; comme l'épopée, comme le Volkslied, il était une création et une révélation de Dieu; dès l'origine des temps il avait surgi spontanément dans l'âme humaine; c'était la voix même de la nature ${ }^{31}$.

L'idée de l'origine divine des contes est primordiale pour comprendre la conception du genre qui sous-tend les KHM. Les Grimm prétendent n'être que les transcripteurs d'authentiques contes populaires, de cette voix de la nature, sans rien apporter de personnel ${ }^{32}$. Leurs idées et leurs méthodes,

31. E. Tonnelat, Les frères Grimm, I9I2, p. 198.

32. J. Grimm précise sa pensée dans sa correspondance avec A. von Arnim, dont plusieurs extraits intéressants sont cités par A. Jolles, à l'instar de celui-ci : «Si tu crois avec moi que la religion est partie d'une révélation divine et que le langage a une origine tout aussi admirable et n'est pas le produit d'une intervention humaine, cela doit te suffire pour croire et pour sentir que la poésie ancienne et ses formes, que la source de la rime et de l'allitération, sont également parties d'un tout et qu'il ne peut être question de l'atelier ou des médiations de poètes individuels.» (A. Jolles, Formes simples, 1972, p. 176; "Glaubst du mit mir, daß Religion von einer göttlichen Offenbarung ausgegangen ist, daß die Sprache einen ebenso wundervollen Ursprung hat und nicht durch Menschenerfindung zuwege gebracht worden ist, so mußt Du schon darum glauben und fühlen, daß die alte Poesie und 
véhiculées par leur préface et la Circulaire de Jacob Grimm, ont fait des émules au Danemark. D'une part, les KHM ont été rapidement traduits en danois. Adam Oehlenschläger, l'un des écrivains les plus influents de l'époque, en a sélectionné quelques-uns dès 1816, leur donnant ainsi une reconnaissance littéraire très importante. La traduction intégrale du premier volume des KHM, basée sur l'édition de I819, paraît ensuite en I82I. Elle contient la préface et le texte sur la nature des contes ("Ueber das Wesen der Märchen»), qui sont deux documents importants pour faire passer les idées des Grimm au Danemark ${ }^{33}$. D'autre part, les travaux des deux frères sur les légendes allemandes et les vieilles chansons danoises sont bien connus au Danemark, où les Grimm correspondent avec plusieurs chercheurs et écrivains. C'est ainsi, par exemple, que J. M. Thiele a entrepris un travail fondé sur celui des Grimm, qui donnera lieu à des recueils de Danske Folkesagn (Légendes populaires danoises) publiés entre I8I8 et I823. Mathias Winther, nous l'avons vu, publie en 1823 le premier recueil de contes populaires danois. Sa préface fait explicitement référence aux Grimm et les textes sont suivis de remarques indiquant, selon le modèle de ces derniers, des parallèles avec d'autres versions de la même histoire. La conception du genre, enfin, est directement basée sur celle des Grimm, dont les KHM sont l'étalon à l'aune duquel seront jugés les Eventyr, fortalte for Børn.

Or Andersen aspire justement à créer un genre nouveau. Quand il annonce vouloir publier un cycle de contes populaires danois dès $1830^{34}$, il n'entend pas un recueil dans le style de celui de Winther; il ne cherche pas à recueillir et retranscrire des contes populaires danois, mais s'inspire au contraire des Kunstmärchen de J. K. A. Musäus, et plus largement des textes de ses modèles romantiques allemands ${ }^{35}$. S'il dit se servir des contes qu'il a entendus dans son enfance, c'est donc comme source pour son travail d'écrivain, pour raconter «à sa façon", comme il l'écrit dans sa préface citée ci-dessus. Andersen distingue d'une part le folklore de la

ihre Formen, die Quelle des Reims und der Alliteration ebenso in einem Ganzen ausgegangen ist, und gar keine Wekstätten order Überlegungen einzelner Dichter in Betracht kommen können. ", A. Jolles, Einfache Formen, 1974, p. 222-223).

33. Sur les traductions des KHM en danois, voir l'ouvrage très complet de C. Dollerup (C. Dollerup, ouvr. cité, 1999) et l'article de K. Pulmer (K. Pulmer, "Zur Rezeption der Grimmschen Märchen in Dänemark», 1988).

34. H. C. Andersen, Digte, i83o, p. 106.

35. "Autour de Noël I829 sortit un petit recueil de Poèmes, qui s'achevait par un conte en prose "Le mort", que j'avais entendu enfant et racontais maintenant dans un ton qui devait ressembler à celui de Musäus, mais cela ne prit pas avant qu'il paraisse, après plusieurs années, raconté différemment, sous le titre "Le compagnon de voyage"." (H. C. Andersen, ouvr. cité, I963-1990, vol. 6, p. 3, je traduis.) 
littérature, et d'autre part son travail d'écrivain qui crée un nouveau genre littéraire de celui d'auteurs comme les Grimm qui recueillent des contes populaires. Dans son journal, on peut lire une anecdote où il se défend d'avoir repris un texte des Grimm en précisant qu'ils n'ont jamais écrit un conte et n'étaient que des collecteurs ${ }^{36}$. L'idée même d'utiliser la matière des contes populaires pour créer des textes littéraires va à l'encontre de ce que préconisent les $\mathrm{Grimm}^{37}$.

\section{Les manières de raconter}

Les différences entre ces deux projets que sont les KHM et les Eventyr, fortalte for Børn se manifestent au niveau linguistique dans la manière de raconter les histoires. La conception que les Grimm ont du conte comme voix de la nature entraîne une recherche de simplicité et de pureté ${ }^{38}$. Ils ont développé, d'édition en édition, une manière de raconter très spécifique en favorisant les phrases et les propositions courtes assemblées de manière paratactique, mais aussi en développant une certaine utilisation du discours rapporté, en organisant les événements prioritairement à l'aide de "und» et de "da", ou en rythmant leurs textes à l'aide de répétitions ${ }^{39}$. Certains de ces aspects apparaissent bien dans la comparaison des débuts des textes des éditions de I8I2 et I8I9 (voir la note 50).

Lorsque le projet des Grimm est repris au Danemark, cette manière de raconter est valorisée et trouve d'importants échos, comme l'indique Karin Pulmer au sujet de Winther : «Le fait que les contes [...] paraissent familiers dès le premier regard s'explique par les échos indéniables du ton des contes des Grimm.» ("Dass die Märchen [...] auf den ersten Blick vertraut anmuten, erklärt sich durch ihre unverkennbaren Anklänge an den Grimmschen Märchenton ${ }^{40}$.») Le style des Grimm est même érigé en modèle par Christian Molbech, linguiste et historien danois qui encense la «prose

36. 29 mai I873; H. C. Andersen, ouvr. cité, I97I-1977, vol. Io, p. 93.

37. Grimm, ouvr. cité, I8I2, p. XIx. Précisons tout de même qu’Andersen n’a utilisé que sept contes reconnus comme populaires par les folkloristes sur les 156 qu'il a publiés, neuf si l'on ajoute Le Jardin de Paradis et La Princesse sur le pois qu'Andersen dit avoir entendus dans son enfance (voir E. M. Kofod, De vilde Svaner og andre folkeeventyr, 1989, p. II).

38. Voir leur préface : Grimm, ouvr. cité, 1857, vol. I, p. 2I-22.

39. E. Tonnelat donne une liste plus étendue de transformations opérées de la première à la dernière édition pour parvenir à ce style si particulier des Grimm (E. Tonnelat, Les contes des frères Grimm, I9I2); voir aussi le livre de O. Robinson.

40. K. Pulmer, «Zur Rezeption der Grimmschen Märchen in Dänemark», 1988, p. I89, je traduis. 
épique» des KHM dans la préface d'un recueil de contes contenant plusieurs textes des Grimm ${ }^{41}$. C'est une manière de raconter qui est aux antipodes de celle d'Andersen, dont le premier conte, Dødningen (Le mort), a été vivement critiqué par le même Molbech parce que «l'auteur a manqué le ton épique avec lequel les contes doivent être racontés ${ }^{42}$.

C'est à la fois une " révolution de la langue danoise écrite ${ }^{43}$ » et une révolution de la langue du conte inspirée des Grimm que propose le premier cahier d'Eventyr, fortalte for Børn. Là où les contes populaires (folkeeventyr) à la Winther se focalisent sur la succession des événements, Andersen ajoute de nombreux détails qui rendent les personnages vivants devant nos yeux ${ }^{44}$. Dans sa comparaison de De vilde Svaner et De elleve Svaner, Johan de Mylius relève que les différences entre le texte très court de Winther et celui bien plus long d'Andersen s'expliquent par le développement de trois aspects : la description individualisée des personnages; les dialogues scéniques; le pittoresque. Ce dernier aspect, qui se manifeste dans De vilde Svaner par des descriptions détaillées de paysages semblables à des "tableaux", est particulièrement populaire dans la littérature danoise de l'époque ${ }^{45}$. Andersen investit ainsi les non-dits des contes de Winther. Il en découle qu'un texte comme De vilde Svaner est jugé comme très littéraire ${ }^{46}:$ "Andersen ne peut avoir raconté ainsi par oral, c'est une forme écrite très littéraire ${ }^{47} »$. On ne peut toutefois pas simplement conclure qu'Andersen a écrit des contes populaires avec un langage littéraire, car, comme le suggère la révolution dont parle J. de Mylius, l'auteur des Eventyr, fortalte for Børn a transformé

4I. C. Molbech, Udvalgte Eventyr og Fortallinger, I843, p. XIV-XV.

42. Maanedskrift for Litteratur, vol. 3, I830, p. 162-172; cité dans H. C. Andersen, ouvr. cité, 1963I990, vol. 6, p. I4I, je traduis. J'étudie le rôle important de C. Molbech dans la conception du genre eventyr au Danemark dans C. François, art. cité, 2009. Voir aussi U. Heidmann, art. cité, 2007.

43. J. de Mylius, "Andersens anden revolution», 1988, p. 37.

44. Voir J. Tveden, Hvad sproget gør, 2004, p. I49.

45. J. de Mylius, Forvandlingens Pris, 2005, p. I82-2II. Ce chapitre du livre est repris de manière abrégée dans un numéro d'Études germaniques. On lit au sujet de cette mode du "réalisme poétique", qui se développe dès les années I 820 au Danemark, que "le pittoresque devient la méthode même de la description et de l'exploration du monde environnant" (J. de Mylius, "L'écrivain ne cède pas la place au peintre”. La première esthétique de H. C. Andersen", 2003, p. 539).

46. Il est intéressant de relever qu'Andersen, qui utilise très fréquemment le connecteur " for» (parce que) dans ses contes, utilise à une exception près uniquement le «thi» dans De vilde Svaner. Les deux connecteurs ont le même sens, mais «for» est plus usité à l'oral, alors que «thi» est préféré dans la langue écrite. Lorsqu'il réécrit Dødningen (Le Mort, 1830) en Reisekammeraten (Le Compagnon de voyage, I835) pour le faire correspondre à la façon si caractéristique de raconter qu'il est en train de développer, Andersen supprime justement les «thi» et multiplie les "for». La présence importante de «thi» dans De vilde Svaner indiquerait-elle une dimension littéraire plus classique dans ce texte que dans les autres contes?

47. J. de Mylius, «H. C. Andersen / Forfatterportræt», je traduis. 
la langue danoise, notamment en dissolvant «la phrase simple et d'une forme grammaticalement parfaite, qui constituait l'idéal de la prose de l'Âge d'or, chez Heiberg et d'autres, [...] au profit de propositions elliptiques ou d'anacoluthes ${ }^{48}{ }^{8}$. Il invente ainsi une forme de langue littéraire oralisée là où cette prose se distinguait formellement de la langue orale ${ }^{49}$.

\section{Chacun son rythme}

Les grandes différences entre les Grimm et Andersen dans la manière de raconter sont visibles dès le début des textes. Observons celui de Die sechs Schwäne, dans l'édition de I8I9 qui servit de source à la traduction danoise de J. F. Lindencrone en $182 \mathrm{I}^{50}$ :

Es jagte einmal ein König in einem großen Wald und jagte einem Wild so eifrig nach, daßniemand von seinen Leuten ihm nachfolgen konnte, zuletzt verirrte er sich und fand keinen Ausgang. Da sah er etwas auf sich zukommen, das ging wie eine alte Frau gebückt und mit wackelndem Kopf und war eine Hexe. Der König redete sie an und sprach: ,zeigt mir doch den Weg durch den Wald. " $O$ ja, Herr König, antwortete sie, wenn ihr meine Tochter heirathen und zur Frau Königin machen wollt, dann solls geschehen, sonst aber nicht und ihr müßt hier bleiben und Hungers sterben, denn ihr kommt nimmermehr ohne mich aus dem Wald. "Der König, dem sein Leben lieb war, sagte in der Angst ja und daraufführte ihn die Alte zu dem Mädchen. Es war sehr schön, aber der König hatte es doch nicht lieb und konnte es nicht ohne heimliches Grausen ansehen. Die Hexe brachte sie beide auf den Weg nach des Königes Schloß und als sie da angelangt waren, mußte er Wort halten und sie zu seiner Gemahlin nehmen.

Un roi chassait un jour dans une grosse forêt et pourchassait un animal avec tant d'ardeur qu'aucun de ses gens ne put le suivre, finalement il se perdit et ne trouva aucune sortie. Alors il vit quelque chose venir à lui, qui marchait comme une vieille femme voûtée et avec une tête qui dodelinait et c'était une sorcière. Le roi s’adressa à elle et dit : «Montrez-moi donc le chemin pour sortir de la forêt. — Ô oui, Monsieur

48. P. E. Sørensen, «La peine de cœur du langage», 2007, p. 40.

49. Voir aussi J. Tveden, ouvr. cité, 2004, p. I53.

50. Dans l'édition de I8I2, le début du texte est très différent : «Un roi chassait dans une grande forêt, se perdit et ne put trouver aucune issue, alors il vint enfin à une sorcière, à laquelle il demanda si elle voulait bien le guider vers l'extérieur. Mais la sorcière répondit que cela n'arriverait jamais, qu'il devrait rester ici perdre la vie, et que la seule chose qui puisse le sauver était d'épouser sa fille.» ("Ein König jagte in einem großen Wald, verirrte sich und konnte keinen Ausgang finden, da kam er endlich zu einer Hexe, die bat er, sie mögte ihn wieder heraus leiten. Die Hexe aber antwortete, das geschähe nimmermehr, er müsse darin bleiben und sein Leben verlieren, und nur das eine könne ihn erretten, daß er ihre Tochter heirathe.", Grimm, ouvr. cité, I8I2, p. 220, je traduis). Les Grimm ont pris soin de développer le dialogue au discours direct dans l'édition de I8I9. On voit aussi que les propositions ont été réparties en phrases contenant chacune une idée différente (se perdre à la chasse, rencontrer une sorcière, engager un dialogue), alors que la version de 1812 mélange le tout en une seule phrase très dense. 
le Roi, répondit-elle, si vous voulez épouser ma fille et en faire Madame la Reine, alors cela se fera, mais sinon pas et vous devrez rester ici et mourir de faim, car vous ne sortirez jamais de cette forêt sans moi.» Le roi, qui tenait à la vie, dit oui dans la crainte et là-dessus la vieille le conduisit à la jeune fille. Elle était très belle, mais le roi ne l'aimait quand même pas et ne pouvait pas la regarder sans une terreur secrète. La sorcière les mena tous deux sur le chemin du château du roi et quand ils furent arrivés, il dut faire un discours et la prendre pour épouse ${ }^{\text {厂I }}$.

Les propositions sont courtes et le rythme correspond à une succession rapide d'actions liées principalement à l'aide du connecteur «und» (et; onze occurrences pour coordonner des propositions, une pour coordonner des groupes nominaux). Le récit est orienté sur l'action et les phrases comportent peu de circonstancielles.

La situation est bien différente dans le texte d'Andersen, où le narrateur s'investit dans le récit et ne se limite pas à une succession d'actions :

Langtborte herfra, der hvor Svalerne flyve hen, naar vi have Vinter, boede en Konge, som havde elleve Sonner og een Datter, Elisa. De elleve Brodre, Prindser vare de, gik i Skole med Stjerne paa Brystet og Sabel ved Siden; de skreve paa Guldtavle med Diamantgriffel og laste ligesaa godt udenad, som indeni; man kunde strax høre, at de vare Prindser. Sosteren Elisa sad paa en lille Skammel af Speilglas og havde en Billedbog, der var kjøbt for det halve Kongerige.

$O$, de Børn havde det saa godt, men saaledes skulde det ikke altid blive!

Deres Fader, som var Konge over hele Landet, giftede sig med en ond Dronning, der slet ikke var de stakkels Børn god; allerede den forste Dag kunde de godt marke det; paa hele Slottet var der stor Stads, og saa legede Børnene: komme Fremmede; men istedetfor at de ellers fik alle de Kager og stegte Abler, der vare at overkomme, gav hun dem kun Sand $i$ en Theekop og sagde, at de kunde lade, som om det var noget ${ }^{52}$.

Bien loin d'ici, là où vont les hirondelles quand nous sommes en hiver, habitait un roi qui avait onze fils et une fille, Élisa. Les onze frères, c'étaient des princes, allaient à l'école avec une étoile sur la poitrine et un sabre au côté; ils écrivaient sur des ardoises d'or avec un crayon de diamant et lisaient aussi bien à livre ouvert que fermé; on entendait tout de suite que c'étaient des princes. Leur sœur Élisa était assise sur un petit tabouret de verre de miroir et avait un livre d'images qui avait été acheté pour la moitié du royaume.

Oh, tout allait pour le mieux pour ces enfants, mais il ne devait pas en être ainsi pour toujours!

Leur père, qui était roi de tout le pays, se maria avec une méchante reine qui ne fut pas bonne du tout avec les pauvres enfants; ils s'en rendirent compte dès le premier jour ; le château tout entier avait son apparence des grands jours, et les enfants jouaient à recevoir des visites; mais, alors qu'on leur donnait d'habitude tous les gâteaux et les

51. Grimm, Kinder- und Hausmärchen, I819, p. 243-244, je traduis.

52. H. C. Andersen, Eventyr, I963-1990, vol. I, p. I25. 
pommes cuites qu'on pouvait trouver, elle ne leur donna que du sable dans une tasse à thé et dit qu'ils pouvaient faire comme si c'était quelque chose ${ }^{53}$.

Il n'y a que sept «og» (et) dans ce passage, dont quatre coordonnent des groupes nominaux. On voit donc qu'une autre logique narrative lie les propositions dans De vilde Svaner. Si les phrases sont plus longues que dans Die sechs Schwäne, les propositions sont tout aussi courtes, mais le récit n'est pas construit sur une succession d'actions; au contraire, chaque nouvel élément donne lieu à une description qui interrompt la suite des événements et les phrases sont entrecoupées de relatives et d'incises («là où vont les hirondelles quand nous sommes en hiver"; "c'étaient des princes »; "qui était roi de tout le pays») ${ }^{54}$. La description des frères dans le premier paragraphe semble en outre avoir une valeur argumentative. Une incise précise au début que "c'étaient des princes", et on lit plus loin : "on entendait tout de suite que c'étaient des princes"; entre deux, plusieurs éléments décrivent en effet les attributs et les qualités qui confirment leur ascendance royale. Les descriptions ne doivent donc pas être lues comme des interruptions gratuites, des fantaisies du narrateur, mais elles contribuent à la construction du sens.

Ce type de logique narrative se traduit matériellement par une utilisation singulière de points-virgules. Le troisième paragraphe ne présente qu'une seule phrase, mais avec plusieurs propositions séparées par des points-virgules. Il faut en fait lire ce paragraphe comme une grande période où les différents éléments séparés par des points-virgules concourent à décrire la manière dont les enfants sont maltraités par la belle-mère. Si l'on considère l'entier du texte, les six paragraphes des Grimm sont beaucoup plus longs (308 mots par paragraphe en moyenne contre 72 pour Andersen), et contiennent plusieurs actions correspondant à différents épisodes (rencontre de la sorcière dans la forêt; mauvais traitement des enfants par la belle-mère; recherche des frères; épreuve des chemises; épreuve de la belle-mère; dénouement). Les 79 paragraphes de De vilde Svaner, en revanche, contiennent souvent une seule phrase (par exemple les paragraphes 2 et 3 de l'extrait du début du texte), qui ne correspond pas à des épisodes, mais à d'autres types d'entités. La phrase moyenne du texte danois est d'ailleurs plus longue que celle du

53. D'après H. C. Andersen, ouvr. cité, 2005, p. 192. Je modifie parfois les traductions de M. Auchet pour assurer une plus grande proximité avec le texte danois (j'indique alors «d'après» avant la référence). Dans cette citation, $M$. Auchet supprime plusieurs points-virgules sur lesquels j'insiste dans ma démonstration.

54. Die sechs Schwäne présente une relative similaire, mais elle est supprimée par les Grimm dès I837 : «dem sein Leben lieb war» (qui tenait à la vie). 
Märchen (37 mots par phrase contre 24), et plus segmentée (4 virgules par phrase contre 2 chez les Grimm; I47 points-virgules dans l'eventyr, 4 dans les KHM). Par un assemblage paratactique de propositions, Andersen crée une structure périodique formant un tout de sens qui dépasse l'unité de la phrase écrite et qui permet de montrer, de mettre sous les yeux du lecteur ${ }^{55}$.

Les Grimm sont aussi connus pour leur parataxe, mais cette manière d'écrire a une tout autre fonction : les propositions courtes décrivent une succession d'actions, comme dans l'incipit cité ci-dessus. Cette focalisation sur l'action a pour conséquence une grande densité verbale et des propositions souvent réduites au minimum grammatical vital. Dans une étude comparant les textes d'Andersen à des contes populaires danois (folkeeventyr) proches (tirés de recueils de Svend Grundtvig, Evald Tang Kristensen, et aussi de Mathias Winther), Jesper Tveden propose une comparaison basée sur un relevé des natures grammaticales des mots dont les résultats sont similaires à ce que présente le cas Grimm-Andersen ${ }^{56}$. Les contes populaires peuvent selon lui contenir plus de verbes, mais ils contiennent surtout moins de substantifs et d'adjectifs, ce qui s'explique par le manque de précision et de descriptions par rapport aux eventyr d'Andersen. Un sondage sur des passages d'environ 200 mots pris au début et au milieu de De vilde Svaner et Die sechs Schwäne donne des résultats moyens similaires : 2I \% de verbes chez les Grimm contre $19 \%$ chez Andersen ${ }^{57}$; $15 \%$ de substantifs contre 21 \%; $3 \%$ d'adjectifs contre $7 \%$. On trouve également un taux de connecteurs plus important chez les Grimm (Io \% contre 7,6\%), mais la différence est moins importante qu'entre les contes populaires danois et ceux d'Andersen. Les Grimm ont éliminé beaucoup de «und» (et) et de «da» (alors), même s'il en reste énormément, et Andersen tend également à multiplier les " $o g$ " (et), surtout dans les passages plus linéaires où les actions s'enchaînent un peu à la manière des Grimm.

Ces différences linguistiques ne doivent pas uniquement susciter l'intérêt des linguistes. Dans le cas des Grimm comme dans celui d'Andersen, il s'agit de styles très travaillés qui reflètent deux conceptions différentes du

55. La traduction de M. Auchet ne garde qu'un des points-virgules (sur 147), mais propose 159 points de plus que l'original : le rythme est totalement modifié en transformant les longues périodes en phrases courtes, ce qui rend a priori les textes plus lisibles. Les traducteurs tentent ainsi de se rapprocher de la phrase écrite, la correction grammaticale poussant à re-ponctuer le texte, alors que le texte danois est construit sur une autre unité.

56. J. Tveden, ouvr. cité, 2004.

57. Le pourcentage de verbes est assez proche, mais leur utilisation n'est pas la même : alors que la progression est plus linéaire chez les Grimm (une proposition après l'autre), les phrases d'Andersen sont souvent entrecoupées d'incises ou de relatives, comme je l'ai indiqué ci-dessus. 
genre. Quand Andersen écrit ses eventyr, il invente une nouvelle manière de raconter un conte, comme l'avaient déjà fait les Grimm avant lui. Ces derniers cherchent à construire une histoire centrée sur l'action; la moralité n'est pas donnée de manière explicite par un narrateur, mais elle découle des événements qui voient les bons récompensés et les méchants punis. Par la concision et l'enchaînement paratactique d'actions-propositions, ils mettent au point une logique narrative implacable qui donne un aspect " désembrayé» au récit : «Les événements semblent se raconter eux-mêmes ${ }^{58}$ ". Cette dimension correspond à la volonté de représenter le conte comme une émanation de la voix de la nature, et non d'un esprit historiquement et socialement déterminé. Andersen, au contraire, ne s'intéresse pas au squelette du conte populaire (folkeeventyr) tel qu'il est présenté par Winther encore plus succinctement que dans les KHM, mais à ce que l'on peut en faire. Cette histoire d'enfants-cygnes donne lieu, dans De vilde Svaner, à de longs passages descriptifs et oniriques (plusieurs rêves de l'héroïne, un voyage par-dessus les océans, la découverte du château de la fée Morgane, etc.), et la manière de raconter tend à donner à voir au lecteur, à le mettre en présence de ce que ressent l'héroïne. Outre le travail du rythme présenté ci-dessus, Andersen donne à ses eventyr une touche personnelle par la manière dont le narrateur gère sa relation aux lecteurs et aux personnages.

\section{Le rôle du narrateur}

Selon J. Tveden, le narrateur des textes d'Andersen diffère grandement de celui des contes populaires danois auxquels ils sont comparés, en intervenant souvent et en commentant l'histoire :

Fortalleren i folkeeventyret er normalt gemt bag teksten, men i enkelte situationer (oftest $i$ slutningen) kan fortallerene dukke op og give sig til kende med formler som «historien er skam sand nok, for jeg var selv med til bryllupet». Ellers moder vi kun fortalleren glimtvis $i$ de vurderende småord.

Le narrateur des contes populaires est habituellement caché derrière le texte, mais dans certaines situations (le plus souvent à la fin) les narrateurs peuvent apparaître et se manifester avec des formules comme "l'histoire est aussi vraie que vraie, car $j$ 'ai moi-même assisté au mariage». Ou alors nous ne rencontrons le narrateur que par moment dans de petits mots axiologiques ${ }^{59}$.

58. É. Benveniste, Problèmes de linguistique générale, I966, vol. I, p. 24I.

59. J. Tveden, ouvr. cité, 2004, p. 156, je traduis. 
Ce type de formule conclusive se retrouve également chez Andersen ${ }^{60}$, mais le narrateur intervient aussi souvent au début des textes, avec des exclamations et des adresses aux lecteurs ${ }^{6}$. Dans De vilde Svaner, le narrateur crée un lien de connivence avec le lecteur dès l'incipit : "Bien loin d'ici, là où vont les hirondelles quand nous sommes en hiver ${ }^{62} »$. Le présent d'énonciation et l'utilisation des déictiques «ici» et "nous» associent l'énonciateur et le co-énonciateur dans un temps et un lieu communs, assurant ainsi au narrateur un statut de médiateur entre l'histoire et son lecteur ${ }^{63}$. Il n'est donc pas étonnant de lire ce commentaire quelques lignes plus bas : «Oh! tout allait pour le mieux pour ces enfants, mais il ne devait pas en être ainsi pour toujours! ${ }^{64}$ » Le narrateur se présente à la fois comme l'organisateur du récit, en annonçant le nœud, et comme le commentateur de l'histoire. La tournure exclamative exprime en outre son implication émotionnelle ${ }^{65}$. Qu'il soit émerveillé ou inquiet, le narrateur partage souvent ses émotions avec le lecteur dans les eventyr d'Andersen. Plus loin dans le texte, il évalue même ce qu'il est en train de raconter : "[...] et c'était la stricte vérité, ce que disaient les roses et le recueil de cantiques.» ("og det var den rene Sandhed, hvad Roserne og Psalmebogen sagde $\left.{ }^{66} . "\right)$

De vilde Svaner présente moins d'interventions directes avec des déictiques que d'autres contes, comme Lille Claus og store Claus, mais la différence est nette avec Die sechs Schwäne où les commentaires du narrateur se lisent principalement par la composante axiologique de certains adjectifs, comme dans "die falsche Schwiegermutter» (la fausse belle-mère; on lit

6o. Dans Prindsessen paa Arten (La Princesse sur le pois), par exemple : "Voilà, c'était une vraie histoire!» (H. C. Andersen, Contes et histoires, 2005, p. 93; "See, det var en rigtig Historie!", H. C. Andersen, ouvr. cité, I963-1990, vol. I, p. 42).

6. Comme dans Lille Claus og store Claus (Le Petit Claus et le grand Claus), par exemple : «Écoutons maintenant ce qui leur est arrivé, car c'est une vraie histoire!» (H. C. Andersen, Contes et histoires, 2005, p. 77 ; "Nu skulle vi høre, hvorledes de to havde det, for det er en virkelig Historie!», H. C. Andersen, ouvr. cité, I963-1990, vol. I, p. 30).

62. H. C. Andersen, ouvr. cité, 2005, p. 192, je souligne.

63. Notons également que, contrairement à l'incipit des Grimm, celui d'Andersen présente l'histoire dans un monde exotique plus que féerique, situé «loin d'ici», et non pas dans le monde féerique dans lequel nous introduisent des formules comme «Il était une fois» (voir H. Weinrich, Le Temps, I973, p. 46).

64. H. C. Andersen, Contes et histoires, 2005 , p. 192.

65. «Par l'exclamation, le locuteur apporte une information supplémentaire : son sentiment à l'égard de ce qu'il dit" (M. Riegel et al., Grammaire méthodique du français, 1994, p. 387). Ce signe de ponctuation est très usité dans les textes d'Andersen et plutôt rare dans les KHM. On en trouve 43 dans De vilde Svaner (aucun dans Die sechs Schwäne), mais la plupart sont utilisés dans le discours direct ou indirect libre.

66. H. C. Andersen, ouvr. cité, I963-1990, vol. I, p. I26; traduction : H. C. Andersen, ouvr. cité, 2005, p. 194 . 
même «die gottlose Schwiegermutter» — la belle-mère impie — en I8I2) ${ }^{67}$. L'intervention directe du narrateur est l'un des éléments qui posent problème aux Grimm chez leurs contemporains, qui utilisent, selon eux, les contes populaires pour leurs créations personnelles au lieu d'assurer leur "pureté» et leur "authenticité» en ne faisant que les retranscrire, comme les Grimm prétendent le faire eux-mêmes dans leurs KHM. Les contes de L. Bechstein présentent par exemple un narrateur qui n'hésite pas à faire des commentaires et de l'humour pendant le récit. La manière dont Andersen fait raconter ses histoires par un narrateur très présent est à mettre en relation avec son intérêt pour les écrivains romantiques allemands (principalement Tieck et Musäus), qui sont précisément ceux que les Grimm remettent en cause.

La représentation des paroles illustre également la différence d'implication des narrateurs. Les Grimm affichent une nette préférence pour le discours direct sur le discours indirect dans leurs KHM. C'est même une caractéristique qu'ils ont développée lors de la réécriture de leurs textes entre l'édition de I8I2 et celle de I857. La comparaison des débuts de Die sechs Schwäne est très révélatrice à ce sujet avec la représentation d'un dialogue complet et équilibré. Les retrouvailles des frères et sœur présentent également un échange de répliques au discours direct :

Da sah sie das Mädchen an und sah, daß es ibre Brüder waren, freute sich und kroch unter dem Bett hervor. Die Brüder, als sie ihr Schwesterchen erblickten, freuten sich auch, waren aber zugleich traurig und sprachen: "Hier kann deines Bleibens nicht seyn, das ist eine Herberg für Räuber, die vom Raub heimkommen; wenn sie dich fänden, würden sie dich ermorden. "Da sprach sie: „Könnt ihr mich denn nicht schützen?" „Nein, antworteten sie, denn wir können nur eine Viertelstunde lang jeden Abend unsere Schwanenhaut uns abblasen und haben in der Zeit unsere menschliche Gestalt, hernach werden wir wieder verwandelt." „Kann ich euch aber nicht erlösen?" sprach das Mädchen. „Ach nein, antworteten sie, das kannst du nicht, denn es ist zu schwer: sechs Jahre lang darfst du nicht sprechen und nicht lachen, und mußt in der Zeit sechs Hemdlein aus Sternenblumen für uns zusammennähen, sprichst du ein einziges Wort, so ist alle Arbeit verloren. "Und als die Brüder das gesprochen, war die Viertelstunde herum und sie wurden wieder in Schwäne verwandelt.

Alors la jeune fille les regarda et vit que c'étaient ses frères, se réjouit et sortit de dessous le lit. Les frères, quand ils aperçurent leur petite sœur, se réjouirent aussi, mais furent en même temps tristes et dirent : «Ceci ne peut être ta demeure, c'est un repaire de brigands, qui reviennent de brigandages; s'ils te trouvaient, ils te tueraient.» Alors elle dit : «Ne pouvez-vous donc pas me protéger?» «Non, répondirent-ils, car nous ne pouvons retirer notre peau de cygne qu'un quart d'heure chaque soir et nous avons

67. L'axiologie est également une composante importante des textes d'Andersen : «den onde Dronningen" (la méchante reine), "de stakkels Prindser» (les pauvres princes), "den stakkels lille Elisa» (la pauvre Élisa). 
pendant cette période notre forme humaine, après ceci nous nous retransformons.» «Mais ne puis-je pas vous délivrer?» dit la jeune fille. "Hélas non, répondirent-ils, tu ne le peux point, car c'est trop difficile : tu ne dois pas parler pendant six ans, ni rire, et dois pendant ce temps coudre pour nous six chemises d'asters, si tu dis un seul mot, alors tout ton travail est perdu.» Et quand les frères eurent dit ceci le quart d'heure fut écoulé et ils furent de nouveau transformés en cygnes ${ }^{68}$.

L'apport d'information se fait dans le cadre d'un dialogue dans lequel l'héroïne pose des questions et ses frères lui répondent. La représentation sur le mode direct donne une impression de réalité, car les personnages prennent eux-mêmes la parole et tout le dialogue semble rapporté.

La situation est bien différente dans De vilde Svaner. Le discours direct est réservé au long récit du frère aîné («Nous, tes frères, dit le plus âgé, nous volons comme des cygnes sauvages [... ${ }^{69}$ ») et à l'interrogation exclamative d'Élisa ( Comment faire pour vous sauver ? ${ }^{70}$ ), mais il ne représente toutefois pas vraiment un dialogue. Ce qui précède, tout comme ce qui suit, évoque des dialogues que le narrateur choisit de ne pas représenter («ils eurent vite fait de comprendre combien leur marâtre avait été méchante envers eux tous», «Et ils parlèrent ensemble presque toute la nuit » $\left.{ }^{71}\right)$. Il n'y a donc aucune volonté de mettre en scène un dialogue en représentant les répliques sur un mode garantissant prétendument la fidélité. Le narrateur affiche clairement l'opération de sélection qu'il effectue pour mettre en avant certains éléments. Le reste du texte présente d'ailleurs peu de dialogues, mais plutôt des répliques isolées, comme les paroles magiques de la belle-mère au début. Les êtres inanimés ont même souvent le droit à la parole (le vent, la mer, des roses, un livre de psaumes, une icône) et plusieurs discours sont imaginés par le narrateur : "C'était comme si la mer voulait dire : je peux aussi avoir l'air sombre ${ }^{72}$ ». Le narrateur ne se limite ainsi pas à représenter les paroles ou les pensées des personnages, mais il analyse l'histoire et prête des discours à des êtres, animés ou non.

Il tend également à gommer l'hétérogénéité énonciative entre son discours et ceux qu'il représente en favorisant le discours narrativisé et en supprimant les marques propres au discours direct. On peut ainsi lire un discours direct sans verbe introducteur dans un paragraphe où le lecteur est placé au plus près de l'héroïne en suivant ses perceptions (relevons le

68. Grimm, ouvr. cité, I819, p. 245-246, je traduis.

69. H. C. Andersen, ouvr. cité, 2005, p. 199-200.

70. Ibid., p. 200.

7I. Ibid., p. 199-200.

72. D'après ibid., p. 198. 
verbe betrage, «observer») et ses pensées (par le discours indirect libre ${ }^{73}$ souligné ci-dessous) :

Hele det deilige Hav laae for den unge Pige; men ikke en Seiler viste sig derude, ikke en Baad var der at see, hvor skulde hun dog komme langer bort. Hun betragtede de utallige Smaastene paa Bredden; Vandet havde slebet dem alle runde. Glas, Jern, Stene, Alt hvad der laae skyllet op, havde taget Skikkelse af Vandet, der dog var langt blodere end hendes fine Haand. „Det bliver utratteligt ved at rulle, og saa jevner sig det Haarde, jeg vil vare ligesaa utrattelig! tak for Eders Lardom, I klare, rullende Bølger; engang, det siger mit Hjerte mig, ville I bare mig til mine kjare Brodre!" 74

La mer entière s'étendait dans sa beauté devant la jeune fille, mais pas un seul bateau à voile ne s'y montrait, on n'apercevait pas une seule embarcation. Comment faire pour aller plus loin? Elle observa les innombrables petits cailloux sur la rive. L'eau les avait tous polis. Verre, fer, pierres, tout ce qui avait été rejeté là avait pris l'apparence de l'eau, qui était encore bien plus douce que sa petite main délicate. «Elle est infatigable, elle roule sans cesse ses vagues, et ce qui est dur est raboté. Je veux être aussi infatigable! Merci pour votre sagesse, vagues claires avec vos rouleaux. Un jour, c'est ce que me dit mon cœur, vous me porterez jusqu’à mes chers frères! \$5 $^{5}$

Ce sous-marquage ${ }^{76}$ complique l'identification de l'énonciateur dans ce paragraphe où la voix du narrateur et celle de l'héroïne s'imbriquent, dans le discours indirect libre, et dans le discours direct où le pronom initial (elle) renvoie à un antécédent formulé par le narrateur (l'eau), créant un sentiment de continuité qui n'est remis en question qu'avec l'irruption du pronom «je».

\section{Conclusion}

Dans la première moitié du XIX ${ }^{\mathrm{e}}$ siècle, plusieurs textes allemands et danois racontent des histoires d'enfants-cygnes très proches que les auteurs disent issues de la tradition populaire. Une comparaison permet de confirmer la chronologie de ces textes, dont chacun semble réécrire celui qui le précède. Die sieben Schwäne (Feen-Mährchen, I80I) présente une "reconfiguration " importante de l'histoire des enfants-cygnes issue du Dolopathos, en introduisant des éléments qui seront repris dans Die sechs Schwäne (Grimm, I8I2).

73. L'utilisation très importante du discours indirect libre (voir J. Brøndrum-Nielsen, Dakning, I953) contribue à la grande modernité de l'écriture d'Andersen (P. E. Sørensen, art. cité, 2007, p. 40).

74. H. C. Andersen, Eventyr, 1963-1990, vol. I, p. I29.

75. H. C. Andersen, ouvr. cité, 2005 , p. 198.

76. On pourrait aussi relever l'absence de guillemets dans l'exemple cité plus haut — «C'était comme si la mer voulait dire : je peux aussi avoir l'air sombre» —, comme si le narrateur voulait signifier par là qu'il ne s'agit pas d'un vrai discours, mais de paroles imaginées. 
De elleve Svaner (Winther, I823) contient à son tour des éléments des KHM et sert d'intertexte à De vilde Svaner (Andersen, I838). Un lien unit ainsi clairement l'eventyr d'Andersen et le Märchen des Grimm, mais il ne semble pas que l'auteur danois réécrive directement le texte de ses homologues allemands. Le dialogue prendrait plutôt une autre voie : lorsqu'il entreprend le premier cahier de ses Eventyr, fortalte for Børn en 1835, Andersen prend position par rapport à une mode du conte au Danemark qui est directement inspirée des KHM et engage un dialogue avec les formes génériques de son époque (de même que Perrault et les Grimm avant lui) ${ }^{77}$. Il propose une remise en question constante et profonde du genre du conte, comme le propose Isabelle Jan :

Poète, Andersen ne s'est guère soumis à une forme rigide [...] il a refusé la structure même du conte. Et, loin de se couler dans un moule, on peut dire que, dès son premier recueil, il n'a eu cesse de le briser. [...] la tâche de l'écrivain est d'introduire dans cet ordre préétabli et qui tend logiquement vers son propre accomplissement, le désordre. C'est-à-dire une redistribution des choses ..[ $[\ldots]^{78}$

Les différences entre Die sechs Schwäne et De vilde Svaner résultent en effet de deux manières opposées de concevoir le genre : les Märchen sont pour les Grimm l'un des pans de la littérature populaire (Volkspoesie) qu'il s'agit de retranscrire fidèlement; les eventyr présentent pour Andersen un répertoire d'histoires que l'écrivain peut utiliser pour créer des œuvres personnelles. Ces différences se manifestent à la fois au niveau de la structure narrative et au niveau de la manière de raconter. On a vu que le texte allemand est centré sur l'action et que c'est sur la base de leurs faits et gestes que les personnages sont récompensés ou punis, alors que le texte danois introduit de nombreuses descriptions et s'attache à présenter l'héroïne comme une fille pieuse et vertueuse, mais moins active que celle des Grimm. D'autre part, la comparaison a montré des manières de raconter très différentes, avec une présence forte du narrateur qui intervient dans le récit et commente l'histoire, chez Andersen, alors que les KHM fait comme s'il n'y avait pas de narrateur. Il ne faut pas en déduire qu'il manque quelque chose au texte des Grimm, ni qu'ils ne feraient effectivement que retranscrire des contes sans y apporter la touche de l'écrivain. Une étude génétique montre au contraire que le style des KHM est très travaillé et que les modifications effectuées dans les textes, entre I8I2 et I857, portent l’«empreinte caractéristique» de

77. En ce qui concerne Andersen, la comparaison de Fyrtøiet (Le briquet) et Das blaue Licht (La lumière bleue) suggère les mêmes conclusions (U. Heidmann, art. cité, 2007).

78. I. Jan, Andersen et ses contes, I977, p. 48. 
Wilhelm Grimm, comme l'écrivit son frère Jacob en I86o, à l'occasion de son oraison funèbre :

So oft aber ich nunmehr das Märchenbuch zur Hand nehme, rührt und bewegt es mich, denn auf allen Blättern steht vor mir sein Bild und ich erkenne seine waltende Spur.

Désormais, chaque fois que je prends le recueil de contes dans les mains, je suis touché et ému, car son image [celle de Wilhelm] se présente à moi sur toutes les pages et je reconnais son empreinte caractéristique ${ }^{79}$.

C'est donc bien sur une question de plumes que ces deux histoires d'enfants-cygnes different, mais il s'agit de celles des auteurs, qui les racontent selon la conception qu'ils se font du genre "conte» (Märchen ou eventyr) et le projet qu'ils entreprennent avec leurs Kinder-und Hausmärchen et leurs Eventyr, fortalte for Børn.

\section{Bibliographie}

\section{Textes}

Andersen Hans Christian, Contes et histoires, trad. M. Auchet, Paris, Le Livre de Poche, 2005.

—, Euvres, trad. R. Boyer, Paris, Gallimard, coll. «La Pléiade», I992, 2 vol.

—, Eventyr, E. Dal (ed.), Copenhague, DSL/Hans Reitzel, I963-1990, 7 vol.

—, H. C. Andersens Dagbøger I825-1875, K. Olsen \& H. Topsøe-Jensen (eds), Copenhague, G. E. C. Gad, I971-1977.

—, Digte, Copenhague, [à compte d'auteur], I83o.

Bechstein Ludwig, Le Livre des contes, trad. C. et Cl. Lecouteux, Paris, José Corti, coll. "Merveilleux», 2oı。.

—, Deutsches Märchenbuch, Leipzig, G. Wigand, I847 [I845].

Dal Erik (ed.), Dansk Folkedigtning, Copenhague, Gyldendal, 1967.

Grimm Jacob et Wilhelm, Contes pour les enfants et la maison, trad. N. Rimasson-Fertin, Paris, José Corti, coll. «Merveilleux», 2009, 2 vol.

-, Kinder- und Hausmärchen, Ausgabe letzter Hand [1857], H. Rölleke (ed.), Stuttgart, Philip Reclam, I997 [1980], 3 vol.

—, Kinder- und Hausmärchen [I8I2 \& I8I5], réimpression augmentée de la première édition de I8I2 et I8I5 d'après la copie personnelle du Musée

79. Cité dans C. Dollerup, ouvr. cité, I999, p. 65, je traduis. H. Rölleke parle quant à lui du «style inimitable» des Kinder- und Hausmärchen, en soulignant le fait que ce style est "créé" par Wilhelm Grimm (H. Rölleke, Die Märchen der Brüder Grimm, 2004, p. 86). 
des Frères Grimm de Kassel, avec toutes les corrections manuscrites et les modifications des frères Grimm, [...] par Heinz Rölleke, Göttingen, Vandenhoeck \& Ruprecht, I986, 2 vol.

-, Kinder- und Hausmärchen, Berlin, G. Reimer, I8I9.

Haute-Seille Jean de, Dolopathos, ou le roi et les sept sages, trad. Y. FoehrJanssens et E. Métry, Turnhout, Brepols, 2000.

Marzolph Ulrich (ed.), Feen-Mährchen: zur Unterhaltung für Freunde und Freundinnen der Feenwelt. Volkskundliche Quellen, Hildesheim, Olms, 2000.

Molbech Christian, Udvalgte Eventyr og Fortallinger. En Lasebog for Folket offor den barnlige Verden, Copenhague, C. A. Reitzel, I843.

Winther Mathias, Danske Folkeeventyr, Copenhague, den Wahlske Bohandlings Forlag, I823.

\section{Études}

Adam Jean-Michel et Heidmann Ute, Le texte littéraire : pour une approche interdisciplinaire, Louvain-la-Neuve, Academia-Bruylant, coll. «Au cœur des textes", 2009.

Benveniste Émile, Problèmes de linguistique générale, Paris, Gallimard, I966, vol. I.

BlÉcourt Willem de, "Metamorphosing Men and Transforming Texts. Some Thoughts on the Genealogy of Fairy Tales", Fabula, n' 52, 20II, p. $280-296$.

Bolte Johannes et Polívka Georg, Anmerkungen zu den Kinder- und Hausmärchen der Brüder Grimm, Leipzig, Hildesheim, T. Weicher, G. Olms, I9I3.

Brøndum-Nielsen Johannes, Dakning - Oratio tecta i dansk litteratur for I870, Copenhague, Festskrift udgivet af Københavns universitet, I953.

Bottigheimer Ruth B., "Les contes médiévaux et les contes de fées modernes", Féeries, n ${ }^{\circ}$ 7, Grenoble, Ellug, 2010, p. 2I-43.

—, "Motif, Meaning, and Editorial Change in Grimms' Tales: One Plot, Three Tales, and Three Different Stories ", dans V. Görög-Karady (éd.), D'un conte... à l'autre. La variabilité dans la littérature orale, Paris, éditions du CNRS, I990, p. 54I-553.

Dollerup Cay, Tales and Translation. The Grimm Tales from Pan-Germanic Narratives to Shared International Fairytales, Amsterdam, John Benjamins Publishing Company, 1999. 
Dreyer K., H. C. Andersen - en brevbiografi, Copenhague, Det Kongelige Bibliotek, 2004. Disponible sur <http://www.kb.dk/elib/mss/hcabio> [consulté le 23/02/20II].

François Cyrille, "Échanges et dialogues intertextuels : l'exemple des contes de Perrault et des frères Grimm ", dans $M$. Bragança et $S$. Wilson (éds), É/change : transitions et transactions dans la littérature française I Ex/change: Transitions et Transactions in French Literature, Oxford, Peter Lang, 20II, p. 43-57.

—, "Transcrire ou raconter à sa façon. étude comparative de l'instance narrative dans "Das Bürle" des frères Grimm et "Lille Claus og store Claus" de Hans Christian Andersen ", dans O. Knechciak (éd.), Langues européennes en dialogue, Genève, Institut européen de l'université de Genève, coll. «Euryopa», 2009, p. 66-80, http://www.unige.ch/ieug/ publications/euryopa.html

Harf-Lancner Laurence, Les Fées au Moyen Âge. Morgane et Mélusine. La naissance des fées, Paris, Champion, 1984.

Heidmann Ute, "Expérimentation générique et dialogisme intertextuel : Perrault, La Fontaine, Apulée, Straparola, Basile», Féeries, n 8, Grenoble, Ellug, 20II, p. 45-69.

—, «Raconter autrement. Vers une poétique de la différence dans les Contes racontés aux enfants de Hans Christian Andersen", dans M. Auchet (éd.), (Re)lire Andersen, Paris, Klincksieck, 2007, p. I03-I2I.

Heidmann Ute et Adam Jean-Michel, Textualité et intertextualité des contes. Perrault, Apulée, La Fontaine, Lhéritier..., Paris, Classiques Garnier, coll. "Lire le XVII ${ }^{e}$ siècle», 20IO.

Holbek Bengt, "Hans Christian Andersen's Use of Folktales», dans H. Ellis Davidson et A. Chaudhri (éds), A Companion to the Fairy Tale, Cambridge, D. S. Brewer, 2003, p. I49-158.

Jan Isabelle, Andersen et ses contes, Paris, Aubier Montaigne, 1977.

Jolles André, Einfache Formen, Legende, Sage, Mythe, Raetsel, Spruch, Kasus, Memorabile, Maerchen, Witz, Tübingen, M. Niemeyer Verlag, coll. «Konzepte der Sprach- und Literaturwissenschaft», I974.

—, Formes simples, trad. A.-M. Buguet, Paris, Seuil, coll. «Poétique», 1972. Kofod Else Marie, De vilde Svaner og andre folkeeventyr: sidestykker til syv af H.C. Andersens eventyr, Copenhague, Foreningen Danmarks Folkeminder, 1989.

Mylius Johan de, Forvandlingens Pris. H. C. Andersen og hans eventyr, Copenhague, Høst \& Søn, 2005.

—, "L'écrivain ne cède pas la place au peintre". La première esthétique de H. C. Andersen ", Études Germaniques, n ${ }^{\circ}$ 58, oct.-déc. 2003, p. 533-554. 
—, "Andersens anden revolution», dans Litteraturbilleder. Estetiske udflugter i litteraturen fra Søren Kierkegaard til Karen Blixen, Odense, Odense Universitetsforlag, 1988, p. 37-60.

—, «H. C. Andersen / Forfatterportræt / Forfatterskabet», dans Arkiv for Dansk Litteratur, Copenhague, Det Danske Sprog- og Litteraturselskab og Det Kongelige Bibliotek. Disponible sur <http://www.adl.dk> [consulté le 23/O2/2OII].

Pulmer Karin, «Zur Rezeption der Grimmschen Märchen in Dänemark», dans Brüder Grimm Gedenken, n 8, I988, p. I8I-203.

Riegel Martin (et al.), Grammaire méthodique du français, Paris, PUF, I994. Robinson Orrin W., Grimm Language: Grammar, Gender and Genuineness in the Fairy Tales, Amsterdam, John Benjamins Publishing Company, 2010. Rölleke Heinz, Die Märchen der Brüder Grimm. Eine Einführung, Stuttgart, Reclam, 2004.

—, "Ein Eichendorff-Zitat in den KHM der Brüder Grimm», dans «Wo das Wünschen noch geholfen hat»: gesammelte Aufsätze zu den Kinderund Hausmärchen der Brüder Grimm, Bonn, Bouvier, coll. "Wupertaler Schriftenreihe Literatur", I985, p. I45-I46.

Roussel Claude, "Le conte et le mythe : histoire des enfants-cygnes», dans Fr. Marotin (éd.), Frontières du conte, Paris, éditions du CNRS, I982, p. I5-24.

Sørensen Peer E., "La peine de cœur du langage. L'univers et le langage des adultes et des enfants dans les Contes d'Andersen ", dans M. Auchet (éd.), (Re)lire Andersen. Modernité de l'auvre, Paris, Klincksieck, 2007, p. 39-59.

Tonnelat Ernest, Les contes des frères Gimm. Etude sur la composition et le style du recueil des Kinder- und Hausmärchen, Paris, Armand Colin, I9I2. —, Les frères Grimm. Leur auvre de jeunesse, Paris, Armand Colin, I9I2.

Tveden Jesper, Hvad sproget gør... H. C. Andersen og folkeeventyrene, Copenhague, Dansklærerforeningens Forlag, 2004.

Uther Hans-Jörg, Handbuch zu den Kinder- und Hausmärchen der Brüder Grimm: Entstehung - Wirkung - Interpretation, Berlin, W. de Gruyter, 2008.

Weber Carl Maria von, Obéron, n ${ }^{\circ}$ spécial L'avant-scène Opéra, $\mathrm{n}^{\circ} 74$, avr. I985.

WeInRICh Harald, Le Temps : le récit et le commentaire, Paris, Seuil, coll. «Poétique», I973.

Wolff Lundholt Marianne et Krogh Hansen Per (éds), When We Get to the End... Towards a Narratology of the Fairy Tales of Hans Christian Andersen, Odense, University Press of Southern Denmark, 2005. 